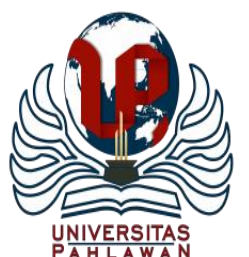

Jurnal Basicedu Volume 5 Nomor 1 Tahun 2021 Halaman 30-40

JURNAL BASICEDU

Research \& Learning in Elementary Education

https://jbasic.org/index.php/basicedu

\title{
Pengembangan Media Lectora Inspire Versi 12 pada Pembelajaran IPA Berbasis STEM untuk Menumbuhkan Karakter Kreatif Siswa
}

\author{
Siti Mayyuthi'i Ristiani ${ }^{1}$, Retno Triwoelandari ${ }^{2}$ Yono $^{3}$ \\ Universitas Ibn Khaldun Bogor, Indonesia ${ }^{1,2,3}$ \\ E-mail : sitimayyuthiiristiani12@gmail.com ${ }^{1}$ retnotriwoelandari@uika-bogor.ac.id ${ }^{2}$ \\ yono@fai.uika-bogor.ac.id ${ }^{3}$
}

\begin{abstract}
Abstrak
Latar belakang pada penelitian ini terdapat beberapa kondisi sebagai berikut : materi yang disampaikan pada pembelajaran IPA masih berfokus kepada buku panduan, kurangnya media pembelajaran yang digunakan, kurang bereksperimen sebagai proses pembelajaran. Tujuan penelitian ini pengembangan media Lectora Inspire versi 12 pada pembelajaran IPA berbasis STEM untuk menumbuhkan karakter kreatif siswa kelas 5 SD/MI. Metode penelitian ini menggunakan metode penelitian dan pengembangan atau research and development dengan menggunakan model ASSURE. Hasil penelitian ahli materi dengan memperoleh presentase kelayakan sebesar $79 \%$ dengan kategori valid, hasil penilaian ahli bahasa sebesar $75 \%$ dengan kategori valid, hasil penilaian ahli media sebesar 69\% dengan kategori valid dan hasil responden uji perorangan sebesar 88\% dengan kategori sangat valid, uji kelompok kecil sebesar 85\% dengan kategori sangat valid dan uji kelompok besar sebesar $87 \%$ dengan kategori sangat valid. Hal ini menunjukkan bahwa produk media pembelajaran Lectora Inspire versi 12 pada pembelajaran IPA berbasis STEM untuk menumbuhkan karakter kreatif siswa layak digunakan dalam proses pembelajaran.
\end{abstract}

Kata kunci: pengembangan media, mata pelajaran IPA berbasis STEM, karakter kreatif

\section{Abstract}

The background in this study is some of the following maten conditions that are presented on the science study are still focused on the manuals, the lack of the media of learning being used, the lack of experimentation as a learning process. The purpose of this study is a version 12 of a lectora-based STEM science study to develop creative $5^{\text {th }}$ grade students. The methods of research use your research and development using your model of resistance. The results of a material expert study by obtaining a 79\% in valid category of worthiness, the linguist's assessment by 75\% in valid categories, $69 \%$ of the media expert's assessment by valid category and $88 \%$ of individual test by highly valid category, a small group test of $85 \%$ in the highly valid category, and a large group test $87 \%$ in the highly valid category. This suggests that a version of lectora learning 12 media product on STEM based science-learning to develop student creative carachter is worthy of use in the learning process.

Keywords: media development, stem based science subjects, creative character

Copyright (c) 2021 Siti Mayyuthi’i Ristiani, Retno Triwoelandari, Yono

$\triangle$ Corresponding author

Address : Universitas Ibn Khaldun

Email : sitimayyuthiiristiani12@gmail.com

ISSN 2580-3735 (Media Cetak)

Phone :-

ISSN 2580-1147 (Media Online)

DOI :https://doi.org/10.31004/basicedu.v5i1.613 


\section{PENDAHULUAN}

Pendidikan dalam bahasa Latin disebut educare, secara konotatif bermakna melatih. Dalam dunia pertanian dikenal istilah educere yang berarti menyuburkan, mengolah tanah menjadi subur agar tanaman dapat tumbuh dengan baik dan menghasilkan sesuai dengan yang dihasilkan (Aisyah dan Ali, 2018).

Pendidikan adalah salah satu bentuk perwujudan yang sangat penting, karena dengan adanya pendidikan siswa dapat tumbuh kembang dengan baik dari segi ilmu pengetahuan atau sikap. Menurut Irianto, (2011) Pendidikan juga dapat menjadi instrumen untuk memupuk kepribadian bangsa, memperkuat identitas nasional dan memantapkan jati diri bangsa.

Pada era globalisasi saat ini pendidikan sudah memasuki zaman yang lebih maju dan modern. Seharusnya siswa dapat terlihat aktif dalam belajar dan memiliki sikap yang baik di lingkungan sekolah atau diluar lingkungan sekolah. Namun, beberapa siswa masih belum memiliki karakter dengan baik sehingga, siswa masih kurang semangat dalam proses pembelajaran. Hal tersebut dikarenakan seorang guru hanya memberikan materi dan fokus kepada satu sumber saja serta tidak terlalu memperhatikan karakter peserta didik dengan baik. Ketika di dalam kelas siswa tidak hanya duduk manis kemudian mendengarkan penjelasan guru dari awal sampai akhir pembelajaran, mengerjakan tugas dan pulang begitu saja. Peserta didik harus memiliki semangat dalam belajar sampai menunjukkan kemampuan yang dimiliki peserta didik saat belajar dan memiliki karakter yang baik.
Menurut Koesoema, (2010) pendidikan karakter merupakan keseluruhan dinamika relasional antar pribadi dengan berbagai macam dimensi, baik dari dalam maupun dari luar dirinya, agar pribadi itu semakin dapat menghayati kebebasannya, sehingga ia dapat semakin bertanggung jawab atas pertumbuhan dirinya sendiri sebagai pribadi dan perkembangan orang lain dalam hidup mereka. Sedangkan menurut Wuryanti \& Kartowagiran, (2016) karakter sebagai watak moral merupakan pengembangan dan perpaduan antara nilai dan sikap dalam bertindak. Karakter juga sebagai aktivitas kehidupan manusia maupun lingkungan yang diwujudkan dalam pikiran, sikap, perasaan, perkataan dan perbuatan berdasarkan norma-norma agama, hukum, tata krama, budaya dan adat istiadat (Yunita et al., 2019).

Sebelum memulai menerapkan karakter kepada peserta didik maka seorang guru harus memulai lebih dulu untuk memperbaiki karakter yang ingin diterapkan kepada peserta didik. Menurut Kemendiknas dalam Ahmadi,Farid dan Ibda, (2018) ada 18 pilar karakter dasar yaitu : 1) religius 2) jujur 3) toleransi 4) disiplin 5) kerja keras 6) kreatif 7) mandiri 8) demokratis 9) rasa ingin tahu 10) semangat kebangsaan atau nasionalisme 11) cinta tanah air 12) menghargai prestasi 13) komunikatif 14) cinta damai 15) gemar membaca 16) peduli lingkungan 17) peduli sosial dan 18) tanggung jawab. Dari kedelapan belas karakter, peneliti akan menumbuhkan karakter kreatif kepada peserta didik untuk meningkatkan karakter kemampuan yang dimiliki peserta didik, karena saat ini dalam pembelajaran 
peserta didik masih kurang terlihat kreatif dan cenderung pasif dalam proses pembelajaran khususnya pada mata pelajaran IPA.

Pengajaran yang diberikan guru di sekolah selama ini masih berfokus kepada materi tanpa melihat kreativitas yang dimiliki peserta didik. Padahal dalam pembelajaran, kreativitas sangat penting untuk diperhatikan guna mengembangkan kemampuan dan bakat yang dimiliki peserta didik dengan optimal dan dapat mengaktualisasikan dirinya. Menurut munandar dalam Kau, (2017) kemampuan berpikir kreatif dapat berkembang secara optimal tergantung pada cara mengajar yang diterapkan oleh guru khususnya pada mata pelajaran IPA. Kemampuan berpikir kreatif juga sangat penting dimiliki oleh peserta didik. Guna menghadapi tantangan dan permasalahan baik di sekolah maupun dalam kehidupan sehari-hari (Mirzon Daheri, Juliana, Deriwanto, 2020).

Dalam pembelajaran IPA saat pembelajaran ada beberapa permasalahan yang ditemukan yaitu : penyampaian materi yang disampaikan guru kurang maksimal, kurang memperhatikan karakter kreatif siswa, kurang menggunakan media pembelajaran yang bervariasi, motivasi, minat belajar kreativitas dan berpikir kritis siswa yang kurang, pendekatan yang diberikan guru kurang maksimal terhadap siswa. Maka dari itu, pelajaran IPA yang dianggap sulit harus bisa diubah menjadi pelajaran yang mudah dan pelajaran yang dianggap membosankan harus bisa diubah menjadi pelajaran yang menyenangkan. Salah satu cara agar pembelajaran dapat mudah dimengerti dan lebih menyenangkan yaitu dengan menggunakan media pembelajaran. Menurut Arsyad, (2014) Media adalah perantara dan pengantar pesan dari pengirim pesan kepada penerima pesan. Pendapat lain Menurut Prasetyo, (2015) Media pembelajaran adalah merangsang siswa untuk mengingat apa yang sudah dipelajari selain memberikan rangsangan belajar baru. Media yang baik juga akan mengaktifkan siswa dalam memberikan tanggapan, umpan balik dan juga mendorong siswa untuk melakukan praktikpraktik dengan benar.

Media yang digunakan harus dapat menarik perhatian peserta didik dalam pembelajaran IPA. karena dengan menggunakan media pembelajaran guru akan terbantu dan lebih mudah untuk menyampaikan materi serta akan membuat siswa semakin semangat dalam belajar. Seorang guru harus bisa berkreatif dan inovatif untuk memilih media pembelajaran yang sesuai dan dapat menumbuhkan karakter pada peserta didik. Apabila guru menggunakan media gambar, maka jangan secara terus menerus menggunakan media gambar atau visual saja. Tetapi harus bergantian sesuai yang dibutuhkan. Apabila hal itu terus terjadi maka pembelajaran akan sama saja membuat peserta didik tidak bersemangat dan sulit untuk memahami pembelajaran.

Untuk menjadikan siswa semangat dalam belajar, maka peneliti tertarik untuk mengembangkan suatu produk, dimana produk ini akan membantu peserta didik lebih kreatif dalam pembelajaran. Produk yang akan dikembangkan oleh peneliti yaitu media pembelajaran Lectora Inspire versi 12 media ini 
dapat digunakan untuk semua pembelajaran khususnya pada mata pelajaran IPA serta dapat menarik perhatian peserta didik dalam proses pembelajaran. Media pembelajaran lectora inspire versi 12 ini dapat dikatakan media paket lengkap, karena terdapat beberapa template, slide-slide yang menarik, gambar bergerak/animation, warnawarna menarik, penskoran dan latihan soal dengan berbentuk game yang dapat menunjukkan perhatian peserta didik. Sehingga ketika pembelajaran berlangsung akan lebih optimal dan menyenangkan. Sebagaimana yang dijelaskan oleh Suryani, Setiawan, (2018) bahwa Lectora Inspire adalah software paket lengkap yang menyediakan beragam template yang siap diisi dengan materi pembelajaran yang akan disajikan. Maka media ini akan lebih mudah untuk membantu guru dalam menyampaikan materi serta dapat menumbuhkan karakter kreatif pada peserta didik.

Selain media pembelajaran Lectora Inspire versi 12 untuk menumbuhkan karakter kreatif peserta didik, maka peneliti akan menerapkan pembelajaran IPA berbasis STEM (sience, technology, engineering and mathematic). Menurut Khairiyah, (2019) STEM adalah salah satu pembelajaran dan strategi yang dipandang sebagai suatu pendekatan yang dapat membuat perubahan yang signifikan pada abad 21 . Pembelajaran IPA dengan berbasis STEM ini akan menciptakan sebuah pembelajaran yang lebih kuat dan bermakna, pembelajaran IPA berbasis STEM juga sangat cocok digunakan di SD/MI. Pendapat lain menurut Utami dalam Artobatama, (2019) mengatakan bahwa STEM dapat meningkatkan pemahaman dalam pembelajaran IPA karena dapat secara langsung mengaitkan konsep pembelajaran ketika diberi pelajaran. Selain itu, menurut Moore dkk dalam Anggraini \& Huzaifah, (2017) STEM merupakan suatu pendekatan dan upaya dalam menggabungkan keempat subjek STEM menjadi satu pelajaran yang didasarkan pada hubungan antara subjek dan masalah dunia nyata.

Dari Permasalahan di atas maka peneliti tertarik untuk melakukan penelitian yang berjudul "Pengembangan Media Pembelajaran Lectora Inspire pada Pembelajaran IPA Berbasis STEM untuk Menumbuhkan Karakter Kreatif Siswa". Peneliti berharap dari penelitian ini siswa dapat menumbuhkan karakter kreatif dalam proses pembelajaran.

\section{METODE}

Penelitian ini termasuk ke dalam jenis penelitian dan pengembangan atau research and development (R\&D). Penelitian dan pengembangan adalah metode penelitian yang digunakan untuk menghasilkan produk tertentu dan menguji keefektifan produk tersebut (Sugiyono, 2016).

Pendapat lain menurut Yusuf, (2017) Penelitian dan pengembangan telah menempati posisi yang paling bermakna, baik di dalam dunia bisnis maupun dibidang sains dan teknologi serta ilmu sosial dan humaniora. Kegiatan penelitian dan pengembangan dilakukan dengan maksud: 1) mengembangkan produk baru, 2) menemukan dan menciptakan ilmu pengetahuan baru tentang model dan hal-hal yang dibicarakan secara ilmiah dan teknologis, dengan tujuan membuka dan memungkinkan untuk menjadi produk baru dan 
sangat berharga, proses lebih efisien serta layanan lebih optimal dan menyenangkan. Sedangkan, menurut Seals dan Richey dalam Hamzah, (2019) penelitian dan pengembangan sebagai suatu pengkajian sistematik terhadap pendesainan, pengembangan, evaluasi program, proses dan produk pembelajaran yang harus memenuhi kriteria validitas, kepraktisan, dan efektivitas.

Berdasarkan pengertian di atas, penelitian dan pengembangan merupakan sebuah ciptaan dan pengembangan produk yang dibuat untuk dapat diaplikasikan pada generasi selanjutnya.

\section{HASIL DAN PEMBAHASAN}

Pengembangan media pembelajaran Lectora Inspire versi 12 pada mata pelajaran IPA berbasis STEM memiliki beberapa langkah untuk mengembangkan media pembelajaran tersebut. Adapun langkah-langkahnya adalah 1) Membuat Garis Besar Program Media (GBPM) 2) Membuat flowchart yang dibuat berupa pembuka, isi hingga penutup 3) Membuat storyboard yaitu uraian berisi visual dan penjelasan dari masing-masing chapter dalam media pembelajaran 4) mengumpulkan bahan-bahan membuat video eksperimen yang akan melengkapi media pembelajaran 5) Programing yaitu dengan merangkai semua bahan yang ada menjadi sebuah produk yaitu media pembelajaran baru. 6) Finishing yaitu dengan publish media pembelajaran agar dapat dikembangkan (Suryono,Sigit, Ary Wahyu, Kurniatno dan Oki, 2011).

Sebelum media pembelajaran digunakan, kegiatan ini memerlukan review dan uji coba oleh para ahli yang mempunyai kemampuan dibidang materi, bahasa dan media.

\section{Hasil Pengembangan Media Pembelajaran Lectora Inspire versi 12}

Setelah melakukan langkah-langkah media pembelajaran Lectora Inspire versi 12 peneliti memulai untuk membuat media pembelajaran dengan menggunakan aplikasi lectora inspire versi 12. Adapun beberapa bukti pengembangan media pembelajaran lectora inspire versi 12 pada mata pelajaran IPA berbasis STEM sebagai berikut :

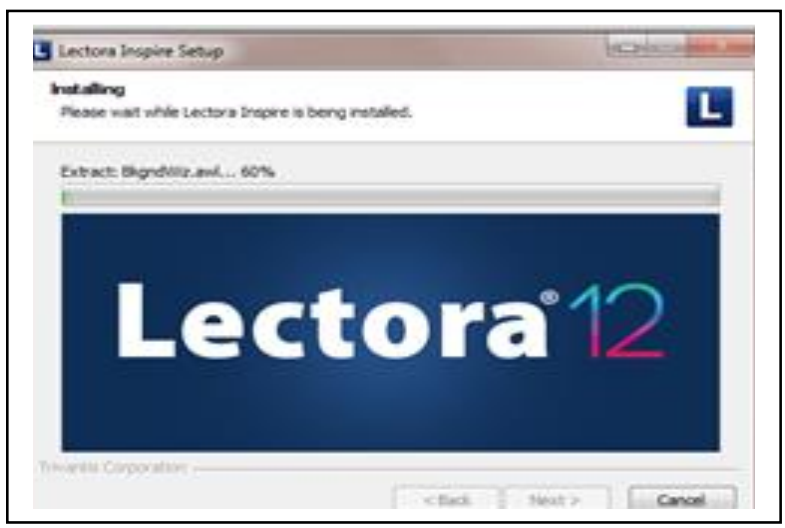

Gambar 1. Menginstal Aplikasi Lectora Inspire Versi 12

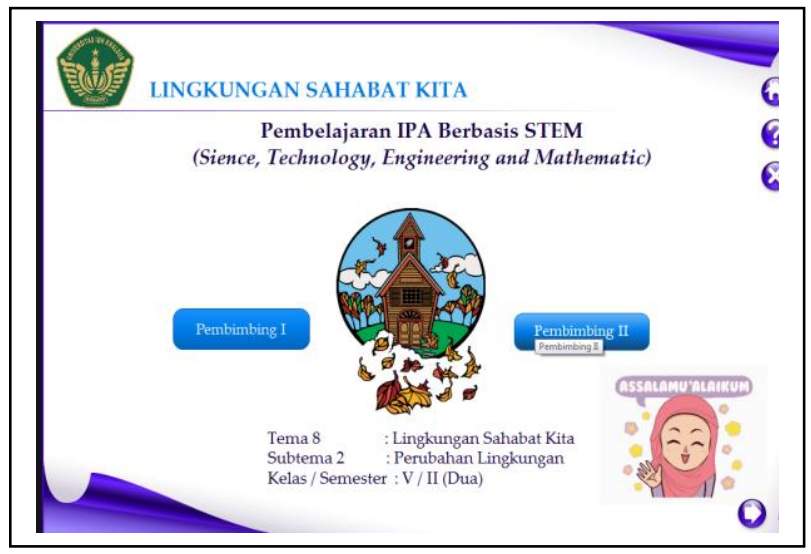

Gambar 2. Tampilan Halaman Depan 
DOI: https://doi.org/10.31004/basicedu.v5i1.613

Pada gambar 1 di atas sebelum peneliti membuat desain media pembelajaran yang pertama dilakukan adalah menginstal aplikasi Lectora Inspire versi 12. Kemudian pada gambar 2 membuat media dengan menambahkan gambar, animasi, botton, warna sesuai dengan karakter peserta didik. Pada gambar 2 tema dan subtema yang akan dibahas yaitu tentang lingkungan sahabat kita "perubahan lingkungan".

\section{Hasil Validasi Ahli Materi}

Dalam uji materi yang menjadi ahli materi yaitu Ibu Retno Triwoelandari, Ir.,M.Pd yang ahli dalam bidangnya. Beliau merupakan dosen Universitas Ibn Khaldun Bogor. Adapun saran dan komentar ahli materi terhadap pengembangan media pembelajaran Lectora Inspire versi 12 yaitu pada slide ke 13 penjelasan materi di pembelajaran ke 3 masih kurang jelas.

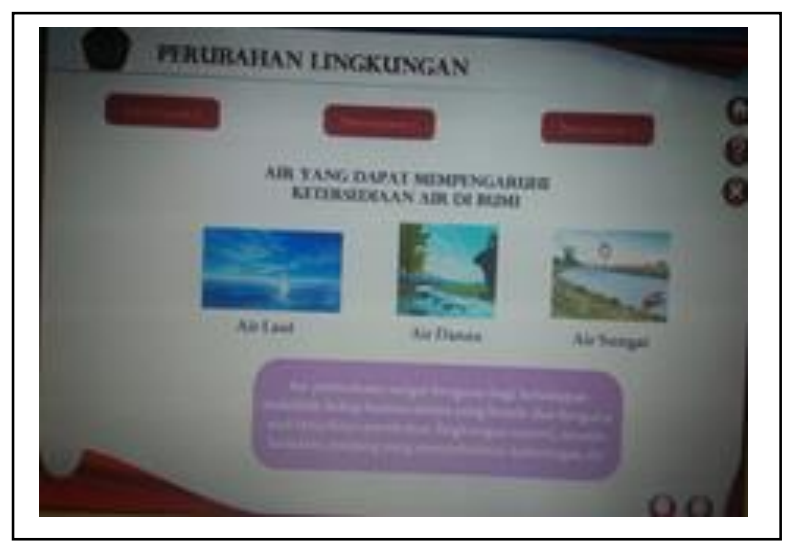

Gambar 3. Materi Sebelum Revisi

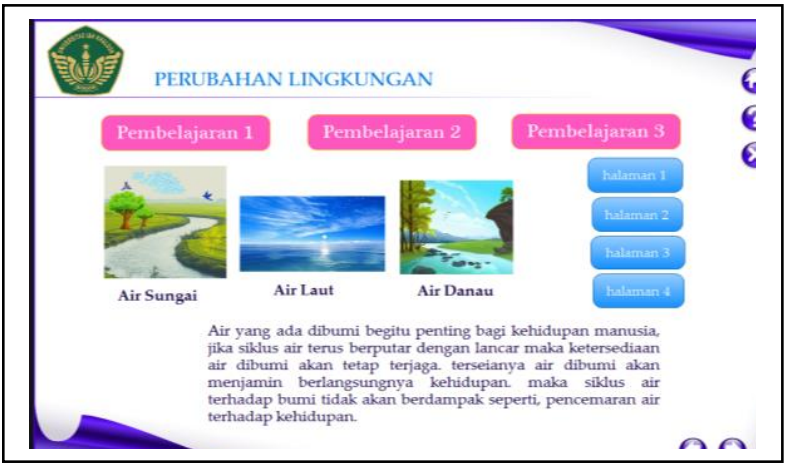

Gambar 4. Materi Setelah Revisi

Pada gambar 3 materi yang dijelaskan tentang dampak siklus air terhadap kehidupan sebelum direvisi dan peneliti memperbaiki materi pada gambar 4 tersebut sesuai saran dan komentar ahli. Adapun nilai ahli materi yang diperoleh sebesar 79\% dengan kategori valid.

\section{Ahli Bahasa}

Dalam uji bahasa yang menjadi ahli bahasa yaitu Ibu Salati Asmahasanah,S.Pd.,M.Pd yang ahli dalam bidangnya. Beliau merupakan dosen Universitas Ibn Khaldun Bogor. Adapun saran dan komentar ahli bahasa tehadap pengembangan media pembelajaran lectora inspire versi 12 yaitu pada slide ke 14 huruf dan font yang digunakan terlalu kecil.

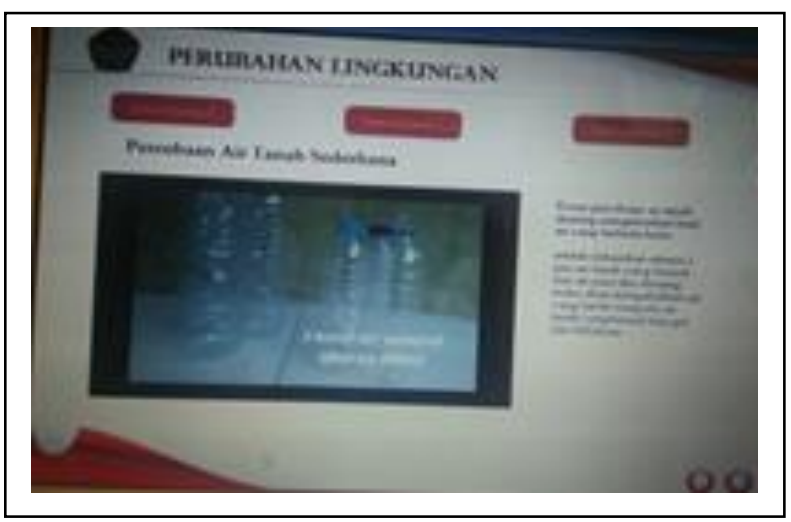

Gambar 5. Slide 14 Sebelum Revisi 
DOI: https://doi.org/10.31004/basicedu.v5i1.613

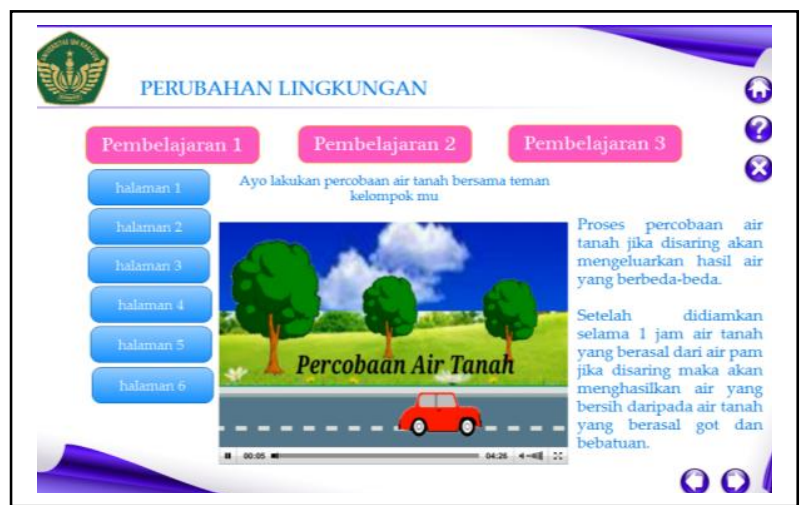

Gambar 6. Slide 14 Setelah Revisi

Pada gambar 5 huruf dan ukuran font yang digunakan pada media pembelajaran lectora inspire versi 12 terlalu kecil dan peneliti mengubah huruf dan ukuran font menjadi besar dan dapat dilihat dengan baik pada gambar 6 . Adapun nilai yang diperoleh ahli bahasa sebesar $75 \%$ dengan kategori valid.

\section{Ahli Media}

Dalam uji media yang menjadi ahli media yaitu Bapak Muhammad Fahri,S.S.,M.Pd yang ahli dalam bidangnya. Beliau merupakan dosen Universitas Ibn Khaldun Bogor. Adapun saran dan komentar ahli media tehadap pengembangan media pembelajaran Lectora Inspire versi 12 sebagai berikut:

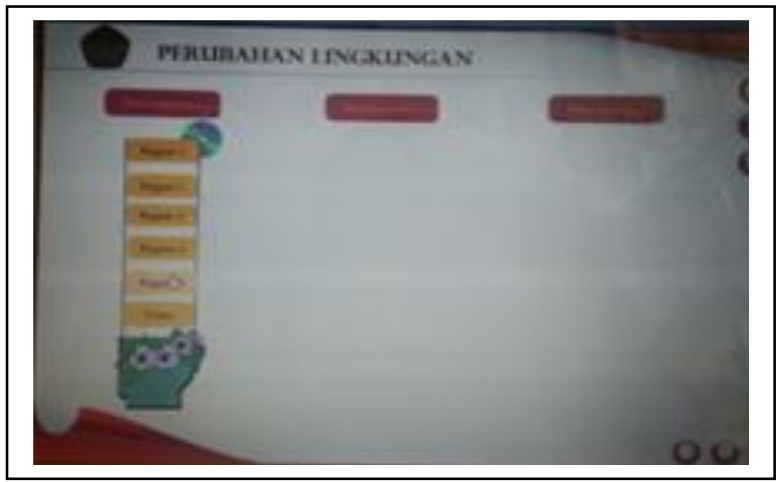

Gambar 7. Slide 8 Sebelum Revisi

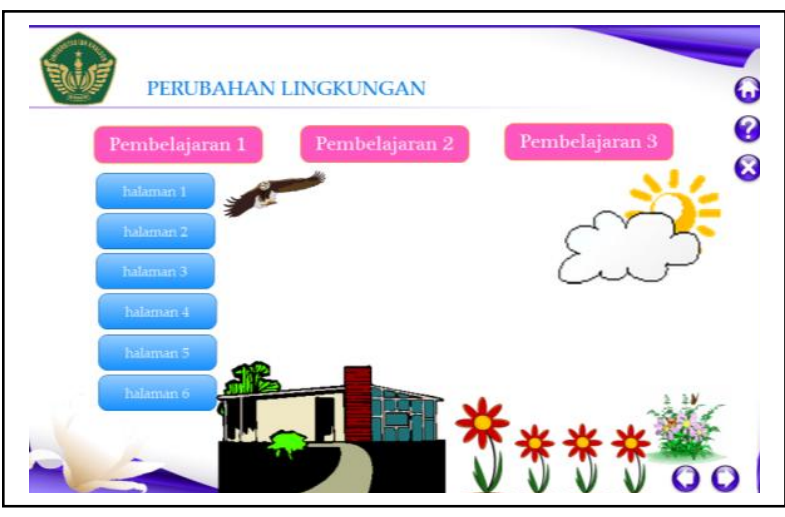

Gambar 8. Slide 8 Setelah Revisi

Pada gambar 7 gambar dan animasi masih terlihat kurang dan warna yang digunakan masih kurang menarik maka, Pada gambar 8 peneliti mengubahnya dengan mengganti template, warna yang menarik dan animasi sesuai dengan karakter peserta didik. Adapun nilai yang diperoleh ahli media sebesar $69 \%$ dengan kategori valid.

\section{Responden Siswa}

Selain dinilai oleh ahli materi, ahli bahasa dan ahli media, maka media pembelajaran Lectora Inspire versi 12 juga diuji cobakan kepada peserta didik. Uji coba terdapat tiga tahapan yaitu, uji coba perorangan, uji coba kelompok kecil dan uji coba kelompok besar. Hasil Penilaian yang diperoleh uji coba perorangan sebesar $88 \%$ dengan kategori sangat valid, hasil yang diperoleh uji coba kelompok kecil sebesar 85\% dengan kategori sangat valid, dan hasil uji coba yang di peroleh kelompok besar sebesar $87 \%$ dengan kategori sangat valid. 
DOI: https://doi.org/10.31004/basicedu.v5i1.613

\section{Keefektifan Media Pembelajaran}

\section{Uji Coba Perorangan}

Uji perorangan ini berupa pengambilan data mulai dari pretest hingga posttest mengenai karakter kreatif siswa dengan menggunakan media pembelajaran Lectora Inspire versi 12 pada mata pelajaran IPA berbasis STEM diberikan kepada 2 responden siswa kelas 5 SDIT Khoiru Ummah. Berikut grafik efktivitas hasil yang didapatkan pada pretest dan posttest :

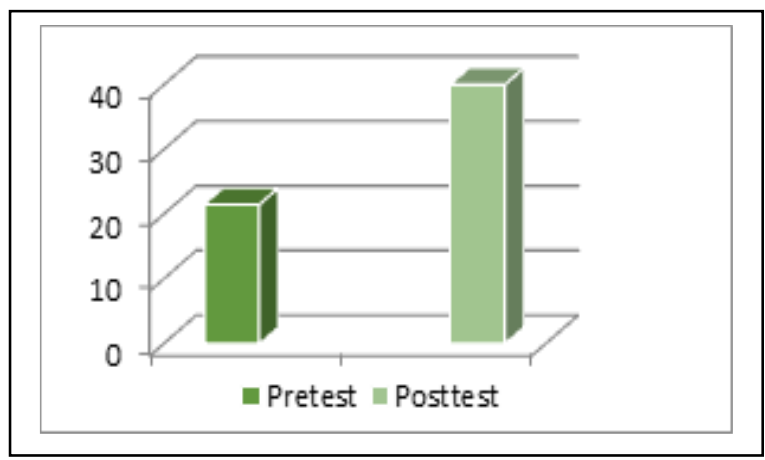

Grafik 1. Efektivitas Uji Coba Perorangan

Berdasarkan pada grafik 1 dapat diketahui bahwa adanya perbedaan antara pretests dan posttest. Hasil tesebut menunjukkan bahwa adanya peningkatan dari hasil pretest dan posttest dengan adanya perbedaan hasil maka, dapat disimpulkan bahwa media pembelajaran Lectora Inspire versi 12 pada mata pelajaran IPA berbasis STEM efektif untuk mengembangkan karakter kreatif siswa.

\section{Uji Coba Kelompok Kecil}

Pada uji coba kelompok kecil ini berupa pengambilan data mulai dari pretest hingga posttest mengenai karakter kreatif siswa dengan menggunakan media pembelajaran Lectora Inspire versi 12 pada mata pelajaran IPA berbasis STEM diberikan kepada 8 responden siswa kelas 5 SDIT Khoiru Ummah. Berikut grafik efktivitas hasil yang didapatkan pada pretest dan posttest :

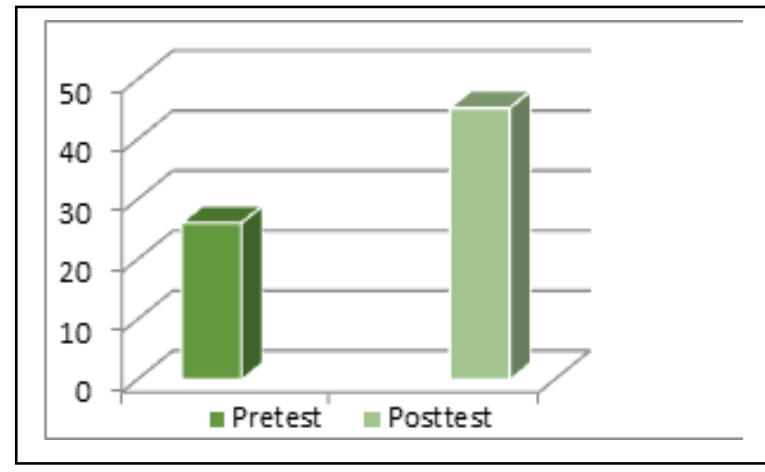

Grafik 2. Efektivitas Uji Coba Kelompok Kecil

Berdasarkan pada grafik 2 dapat diketahui bahwa adanya perbedaan antara pretests dan posttest. Hasil tesebut menunjukkan bahwa adanya peningkatan dari hasil pretest dan posttest dengan adanya perbedaan hasil maka, dapat disimpulkan bahwa media pembelajaran Lectora Inspire versi 12 pada mata pelajaran IPA berbasis STEM efektif untuk mengembangkan karakter kreatif siswa.

\section{Uji Coba Kelompok Besar}

Pada uji coba kelompok besar ini berupa pengambilan data mulai dari pretest hingga posttest mengenai karakter kreatif siswa dengan menggunakan media pembelajaran Lectora Inspire versi 12 pada mata pelajaran IPA berbasis STEM diberikan kepada 15 responden kelas ekperimen dan 15 responden kelas kontrol siswa kelas 5 SDIT Khoiru Ummah. Berikut grafik efktivitas hasil yang didapatkan pada pretest dan posttest : 


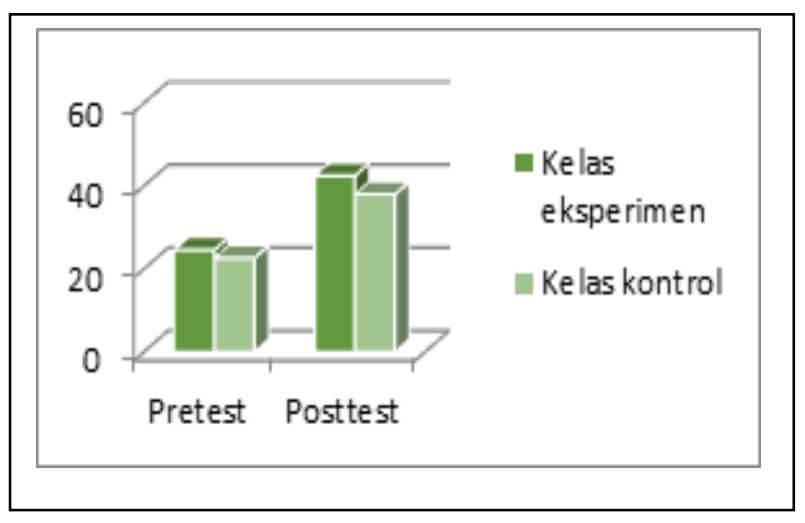

Grafik 3. Efektivitas Uji Coba Kelompok Besar

Berdasarkan pada grafik 3 dapat diketahui bahwa ada perbedaan antara pretest dan posttest. Hasil posttest kelas eksperimen lebih besar dibandingkan hasil posttest kelas kontrol, karena kelas eksperimen diberi perlakuan yang berbeda yaitu pada saat proses pembelajaran menggunakan media pembelajaran Lectora Inspire versi 12. Rata-rata hasil posttest lebih besar dibandingkan hasil pretest sebelum menggunakan media pembelajaran lectora inspire versi 12.

Pengembangan media pembelajaran Lectora Inspire versi 12 pada mata pelajaran IPA berbasis STEM dapat menumbuhkan karakter kreatif siswa. Hal ini menunjukkan dari hasil posttest pada kelas eksperimen dengan nilai rata-rata cukup besar. Maka penggunaan media pembelajaran Lectora Inspire versi 12 pada mata pelajaran IPA berbasis STEM ini efektif digunakan.

Keefektifan media pembelajaran Lectora Inspire versi 12 pada mata pelajaran ini sangat membantu guru dalam penyampaian materi kepada peserta didik dengan mudah dan menarik. Sejalan dengan Lautfer dalam Tafonao, (2018) menjelaskan media pembelajaran sebagai salah satu alat bantu mengajar bagi guru untuk menyampaikan materi pengajaran, meningkatkan kreativitas dan perhatian siswa dalam proses pembelajaran.

Manfaat media pembelajaran menurut Kemp dan Dayton dalam Karo-karo, (2018) adalah, 1) penyampaian materi pelajaran dapat diseragamkan, 2) proses pembelajaran menjadi lebih jelas dan menarik, 3) proses pembelajaran menjadi lebih interaktif, 4) efisiensi dalam waktu dan tenaga 5) meningkatkan kualitas hasil belajar siswa 6) media memungkinkan proses belajar dapat dilakukan dimana saja dan kapan saja 7) media dapat menumbuhkan sikap positif siswa terhadap materi dan proses belajar, dan 8) merubah peran guru ke arah yang lebih positif dan produktif.

Pengembangan media pembelajaran Lectora Inspire versi 12 pada mata pelajaran IPA berbasis STEM sangat dibutuhkan oleh peserta didik dan sebagai penyemangat untuk melaksanakan proses pembelajaran. Media pembelajaran Lectora Inspire versi 12 pada mata pelajaran IPA berbasis STEM ini dapat menumbuhkan karakter kreatif siswa, namun belum secara menyeluruh. Karakter yang dimiliki peserta didik saat ini masih kurang, maka perlu adanya usaha dalam menumbuhkan karakter kreatif siswa. Untuk membantu menumbuhkan karakter kreatif siswa perlu mempersiapkan bahan ajar dengan baik yang dapat memberikan siswa semangat dalam belajar.

Pengembangan media pembelajaran Lectora Inspire versi 12 pada mata pelajaran IPA berbasis STEM sangat membantu guru untuk menyalurkan pesan dan dapat merangsang pikiran peserta didik. Hal ini sejalan dengan pendapat Miarso dalam Dwijayani, (2019) media pembelajaran adalah 
segala sesuatu yang digunakan untuk menyalurkan pesan serta dapat merangsang pikiran, perasaan, perhatian dan kemauan siswa sehingga dapat mendorong terjadinya proses belajar yang disengaja, bertujuan dan terkendali.

Berdasarkan pemaparan di atas, peneliti berpendapat bahwa media pembelajaran Lectora Inspire versi 12 pada mata pelajaran IPA berbasis STEM dapat membantu peserta didik dalam memahami pembelajaran khususnya pada mata pelajaran IPA berbasis STEM, dengan adanya media pembelajaran Lectora Inspire versi 12 siswa dapat bersemangat dalam melakukan proses pembelajaran serta dapat menumbuhkan karakter kreatif siswa. Maka dari itu, pengembangan media sangat perlu dilakukan dengan cara memanfaatkan teknologi dengan baik.

\section{KESIMPULAN}

Pengembangan media pembelajaran Lectora Inspire versi 12 dilakukan dengan 6 tahapan yaitu : 1) Analyze Learning, 2) State Standard and Objective, 3) Select Strategi, Technology, Media and Material 4) Utillize Strategy, Technology, Media and Materials, 5) Require Learner Participation 6) Evaluate and Revise dan 3 tahap uji coba yaitu : uji coba perorangan, uji coba kelompok kecil dan uji coba kelompok besar. Pengembangan media pembelajaran Lectora Inspire versi 12 dilakukan berdasarkan kurangnya penggunaan media dalam proses pembelajaran. Akibat kurangnya media pembelajaran yang digunakan siswa merasa bosan untuk belajar, dengan adanya media pembelajaran Lectora Inspire versi 12 dapat mengalihkan perhatian siswa sehingga dapat fokus untuk belajar dan dapat menumbuhkan karakter kreatif siswa. Media pembelajaran Lectora Inspire versi 12 ini merupakan aplikasi lengkap karena media tersebut terdapat gambar, animasi, musik, template serta warna yang menarik. Media pembelajaran Lectora Inspire versi 12 ini tidak hanya menyampaikan materi saja tetapi bisa membuat soal-soal yang menarik dan dapat membuat siswa bersemangat dalam belajar.

\section{DAFTAR PUSTAKA}

Ahmadi,Farid dan Ibda, H. (2018). Katalog Dalam Terbitan Perpustakaan Nasional Republik Indonesia Media Literasi Teori dan Praktik (D. M. Wijayanti (ed.)). Semarang: CV Pilar Nusantara.

Aisyah dan Ali. (2018). Pendidikan Karakter Konsep dan Implementasinya. Jakarta: Prenada Media.

Anggraini, F. I., \& Huzaifah, S. (2017). Implementasi STEM dalam pembelajaran IPA di Sekolah Menengah Pertama. Prosiding Seminar Nasional Pendidikan IPA 2017. STEM Untuk Pembelajaran Sains Abad 21. 23 September 2017, 1998, 722-731.

Arsyad, A. (2014). Media Pembelajaran (A. Rahman (ed.)). Jakrta: PT Raja Grafindo Persada.

Artobatama, I. (2019). Pembelajaran STEM Berbasis Outbound Permainan Tradisional. Indonesian Journal of Primary Education, 2(2), 40.

Dwijayani, N. M. (2019). Development of circle learning media to improve student learning outcomes. Journal of Physics: Conference Series, 1321(2), 171-187.

Hamzah, A. (2019). Metode Penelitian dan Pengembangan Research \& Development. Malang: Literasi Nusantara Abadi.

Irianto, B. Y. (2011). Kebijakan Pembaruan Pendidikan: Konsep,Teori dan Model. 
Jakarta: PT Raja Grafindo Persada.

Karo-karo, I. R. dan R. (2018). Manfaat Media Dalam Pembelajaran. AXIOM, 7, 91-96.

Kau, M. A. (2017). Peran Guru Dalam Mengembangkan Kreativitas Anak Sekolah Dasar. Proceeding Seminar Dan Lokakarya Nasional Bimbingan Dan Konseling 2017, $O(0)$, 157-166. Khairiyah, N. (2019). Pendekatan Science,Technology,Engineering dan Mathematics (STEM) (Guepedia (ed.)). Indonesia.

Koesoema, D. (2010). Pendidikan Karakter Strategi Mendidik Anak di Zaman Global (A. Nusantara (ed.)). Jakarta: PT Grasindo.

Mirzon Daheri, Juliana, Deriwanto, A. D. A. (2020). Jurnal basicedu. Jurnal Basicedu, $3(2), 524-532$.

Prasetyo, S. (2015). Pengembangan Media Lectora Inspire dalam Pembelajaran Sains di Madrasah Ibtidaiyah. Jurnal Pendidikan Islam, 4(2), 319-337.

Sugiyono. (2016). Metode Penelitian Kuantitatif, Kualitatif, Dan R\&D. Bandung: CV Alfabeta.

Suryani, Setiawan, P. (2018). Media Pembelajaran Inovatif dan Pengembangannya. Bandung: Rosdakarya.

Suryono,Sigit, Ary Wahyu, Kurniatno dan Oki, P. (2011). Pelatihan Pembuatan Media Pembelajaran Berbasis Ict Tahun Pelajaran 2010/2011 Disain Pembuatan Media Pembelajaran Menggunakan Program Lectora

Tafonao, T. (2018). Peranan Media Pembelajaran Dalam Meningkatkan Minat Belajar Mahasiswa. Jurnal Komunikasi Pendidikan, 2(2), 103 .

Wuryanti, U., \& Kartowagiran, B. (2016). Pengembangan Media Video Animasi Untuk Meningkatkan Motivasi Belajar Dan Karakter Kerja Keras Siswa Sekolah Dasar. Jurnal Pendidikan Karakter, 6(2), 232-245.

Yunita, I., Triwoelandari, R., \& Fahri, M. (2019). Pengembangan Media Focusky Terintegrasi Nilai Agama Untuk Mengembangkan Karakter Disiplin Siswa Sekolah Dasar [Development of Integrated Focusky Media on Religious Values to Develop the Discipline Character of Elementary School Students]. PEDAGOGIA: Jurnal Pendidikan, $8(2), 335$.

Yusuf, M. (2017). Metode Penelitian Kuantitatif, Kualitatif dan Penelitian gabungan. Jakarta: PT Fajar Interpratama Mandiri. 